\title{
AC 2012-4523: MOBILE STUDIO PEDAGOGY, PART 1: OVERCOMING THE BARRIERS THAT IMPEDE ADOPTION
}

\section{Prof. Kenneth A. Connor, Rensselaer Polytechnic Institute}

Kenneth Connor is a professor in the Department of Electrical, Computer, and Systems Engineering, where he teaches courses on plasma physics, electromagnetics, electronics and instrumentation, electric power, and general engineering. His research involves plasma physics, electromagnetics, photonics, engineering education, diversity in the engineering workforce, and technology enhanced learning. Since joining the Rensselaer faculty in 1974, he has been continuously involved in research programs at such places as Oak Ridge National Laboratory and the Universities of Texas and Wisconsin in the U.S., Kyoto, and Nagoya Universities in Japan, the Ioffe Institute in Russia, and Kharkov Institute of Physics and Technology in Ukraine. He was ECSE Department Head from 2001-2008 and served on the board of the ECE Department Heads Association from 2003-2008. He is presently the Director of Education for the SMART LIGHTING NSF ERC.

Dr. Dianna L. Newman, University at Albany/SUNY

Mrs. Meghan Morris Deyoe, University at Albany/SUNY

Dr. Craig J. Scott, Morgan State University

Dr. Mohamed F. Chouikha, Howard University

Dr. Yacob Astatke, Morgan State University

Yacob Astatke completed both his doctorate of engineering and B.S.E.E. degrees from Morgan State University (MSU) and his M.S.E.E. from Johns Hopkins University. He has been a full time faculty member in the Electrical and Computer Engineering (ECE) Department at MSU since Aug. 1994 and currently serves as the Associate Chair for Undergraduate Studies. He teaches courses in both analog and digital electronic circuit design and instrumentation. Astatke has more than 10 years' experience in the development and delivery of synchronous and asynchronous web-based ECE courses in the USA and abroad. He is the recipient of the 2012 ASEE Mid-Atlantic Section's Distinguished Teaching Award. 


\title{
Mobile Studio Pedagogy \\ Part 1: Overcoming the Barriers that Impede Adoption
}

\begin{abstract}
The Mobile Studio I/O Board is a small, inexpensive hardware platform for use in a home, classroom or remote environment. When coupled with the Mobile Studio Desktop software, the system duplicates a large amount of the hardware often used to teach Electrical Engineering, Computer Engineering, Control Systems, Physics courses and K-12 technologyoriented courses. The Mobile Studio Project is now being utilized to enhance STEM (Science, Technology, Engineering and Mathematics) education around the world. The project's goal is to enable hands-on exploration of STEM education principles, devices, and systems that have historically been restricted to expensive laboratory facilities. Similar hardware/software platforms are now readily available from a variety of sources, most notably including National Instruments' myDAQ ${ }^{\circledR}$ and Digilent's ${ }^{\circledR} E E$ board. Although the capabilities and costs of these and other systems differ, they all make possible a new approach to education that has the potential to fundamentally change the kind of learning experiences provided for students in STEM disciplines. While previous papers have documented the steady expansion of the number and kind of institutions adopting mobile studio pedagogy and the many positive outcomes of use, many schools are reluctant to switch to this new method due to real and perceived barriers to implementation. The purpose of this paper is to address the barriers, both institutional and instructional, that delay or hinder full implementation and how these barriers have been successfully addressed at sites using the approach.
\end{abstract}

\section{INTRODUCTION}

STEM education at all levels from kindergarten through grad school generally requires expensive, complex equipment; as a result, instruction and learning are typically built around elaborate facilities with well-trained staff support. Use of mobile studio pedagogy supported by Mobile Studio Desktop software and supporting I/O boards, however, makes it possible for instructors and students to participate in hands-on learning any place they have a computer ${ }^{1-9}$. With this access, a full electronics laboratory, for the price of a textbook, is available at any time and any place; students and instructors have a portable lab at their fingertips through which “constructionist learning” is again possible. With a good start provided by interested and dedicated teachers, student accomplishments are limited only by their imagination. Since the Mobile Studio provides a portable lab facility, students can apply the tools they use in the classroom in their personal projects. The most obvious examples involve tinkering with cars (e.g., finding security system workarounds for someone building a car from an early 90's GM drivetrain) and robotics (e.g., adding a real electrical engineering component to a project for a robotics competition). Less obvious are the kinds of student-generated activities that reinforce how exciting and rewarding engineering can be at the personal level-ideas that not only excite the learner/user but also make faculty proud of them (e.g. when students tell us they finished or improved that great idea they had in their high school science fair on their own or students with a physical disability, enrolled in our programs, not only develop new and improved mobility devices but also visit classes in their old high school and show these developments to future STEM professionals). 
When using the Mobile Studio, instructors also are free to "tinker"; they can reconfigure their courses, especially those with significant lab/experimental content, in a number new ways. Through this approach, many instrumentation-based courses and lab based learning experiences can now be held in normal classrooms rather than in specially outfitted facilities. It is no longer necessary to tie students and instructors to the usual lecture, recitation and lab methodology. In addition it is now possible to give hardware-based homework that will allow more rehearsal of knowledge as well as self-generation of information. When the mobile studio approach is expanded to include video lectures, on-line resources and web-based materials, instructors and students are free to organize learning in ways never imagined in the past.

Previous papers have summarized the mobile studio pedagogy, how it has been deployed and utilized in several electrical engineering, general engineering and physics courses, and its impact

on instruction and learning ${ }^{10-15}$. Despite this evidence, many institutions and faculty are hesitant to move to a mobile studio approach due to real and perceived barriers. The purpose of this paper is to discuss these barriers, present evidence that documents their real impact, and override methods that have been shown to counter their presence. These findings and conclusions are based on the aggregated observations and evaluations documenting implementation of the Mobile Studio I/O board and supporting practices and resources across several sites for the past five years. The specific focus of this paper (Part 1) is on the standard use of mobile studio hardware and software as a replacement for the significantly more expensive traditional instruments that are generally used in engineering electronics laboratories. In Part 2, the potential for the much richer student learning experience made possible by mobile studio pedagogy is addressed. While the application of such mobile learning platforms in engineering education remains a work-in-progress, results-to-date provide a convincing argument for rapid adoption.

\section{DESCRIPTION OF THE PROJECT}

\section{2.a. What is the Mobile Studio I/O Board?}

The Mobile Studio I/O board is a small, inexpensive hardware platform developed for use in a classroom or off-campus environment. When coupled with the Mobile Studio Desktop software, the system duplicates a large amount of the hardware often used to teach Electrical Engineering, Computer Engineering, Physics and K-12 technology courses. The purpose of the device is to enable immediate hands-on exploration of STEM education principles, devices, and systems that have historically been restricted to expensive laboratory facilities. Similar hardware/software platforms are now readily available from a variety of sources, most notably including National Instruments ${ }^{\circledR}$ and Digilent ${ }^{\circledR}$. All make possible a new approach to education that has the potential to fundamentally change the learning environment for students in STEM.

The Mobile Studio learning platform originated at Rensselaer Polytechnic Institute (RPI) with support from the National Science Foundation (NSF) Course Curriculum and Laboratory Improvement (CCLI) program with subsequent refinement as it was piloted at Howard University and Rose-Hulman Institute of Technology. Currently, the device is used at these institutions to teach Electrical and Computer Engineering (ECE) courses for both majors and non-majors; essentially all electronics intensive courses at these schools are now taught via the Mobile Studio or a similar platform. With support from the NSF SMART LIGHTING 
Engineering Research Center (RPI is the lead institution), use has been expanded to five other colleges and universities in the United States plus several schools in Africa. Other schools also are now utilizing these tools, supported only by their own resources; for example, another top research university has changed their labs to be mobile studio based; the Mobile Studio is being used at a community colleges and a major scale-up in Africa is about to commence.

A typical experimental configuration for a mobile studio based activity is shown below. The laptop, USB cable and Mobile Studio I/O board and Desktop Software provide the necessary measurement capabilities usually provided by an oscilloscope, a computer interface, (e.g., GPIB) and a computer to store and analyze the data. Using this configuration, the Mobile Studio Desktop Software can save data in a file format compatible with spreadsheets or other analysis tools. The experiment is a cantilever beam with strain gauges mounted on the top and bottom of the beam. The interface circuitry incorporates a Wheatstone bridge and instrumentation amplifier whose output is monitored by one of the Mobile Studio oscilloscope channels. The voltage from the bridge is calibrated to represent the displacement of the beam as it oscillates. Note the characteristic decaying sinusoid of an harmonic oscillator displayed on the laptop screen. This setup is used for a laboratory experiment and a design project in RPI's 'Electronic Instrumentation' course, which is taken by students outside of electrical engineering. ${ }^{17,18}$

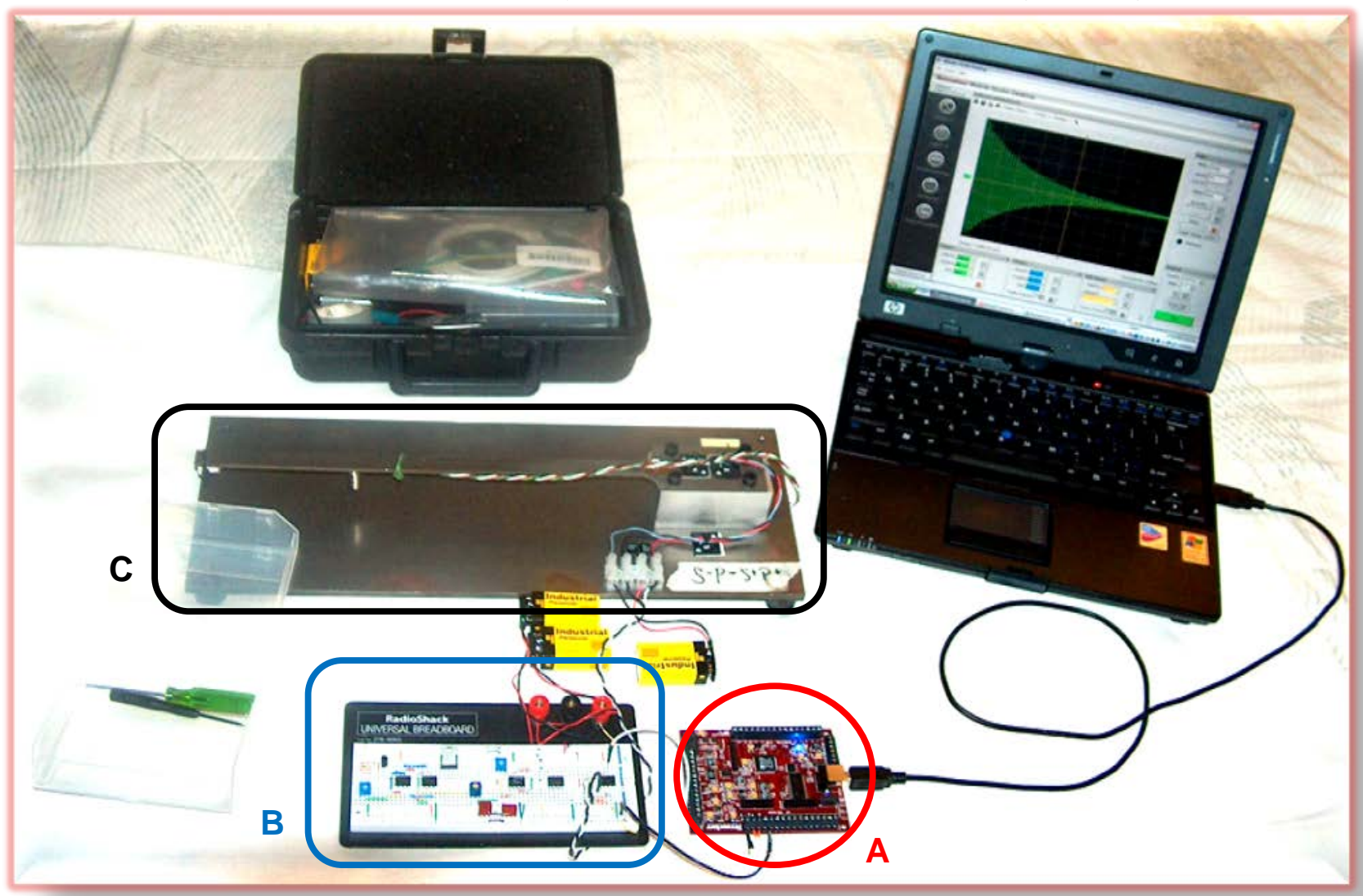

Example of Mobile Studio Experimental Setup for a Cantilever Beam with strain gauges mounted on the top and bottom of the beam: (A) Mobile Studio Board, (B) Interface Circuitry for (C) The Device Under Test. Not labeled are the tool and parts kits, the laptop computer, DC power (9V batteries) and the USB cable. 
The Mobile Studio I/O board shown above is an early version called the RED Board. Recently, this has been replaced by a newer design (RED2) with many additional capabilities (see http://mobilestudioproject.com). The course materials (lectures, lab write-ups, etc.) were all easily updated to accommodate the new hardware, thus demonstrating that switching between similar mobile platforms, such as those from National Instruments ${ }^{\circledR}$ and Digilent ${ }^{\circledR}$ presents no significant barrier to the adoption of this pedagogy. The work is no greater than the kind of update done by most diligent faculty each year.

\section{2.b. Uses of the Mobile Studio Board}

Over multiple semesters, more than 800 students enrolled in five different engineering courses across multiple instructors and semesters at RPI, Rose-Hulman Institute of Technology and Howard University were provided an I/O board for coursework. At RPI, seven classes served primarily electrical engineering students enrolled in an 'Electronic Circuits' course, the course for which the Mobile Studio was first developed. Instructors represented members of the development team as well as non-development faculty. The remaining engineering classes at RPI, 'Introduction to Electronics' and 'Electronic Instrumentation,' depict the transferability of the Mobile Studio. 'Introduction to Electronics' represents use of the Mobile Studio I/O Board in a higher level course within electrical engineering; use was supported by non-development faculty and teaching assistants (in later semesters students had prior experience with the method in the 'Electronic Circuits' course). Use in 'Electronic Instrumentation' illustrated the transfer of the Mobile Studio pedagogy across courses and context to an engineering course for students who do not have a background in electronics; support in this course was provided, across semesters by both developing and non-developing faculty. In addition, the Mobile Studio I/O Board was used in two courses for electrical engineering majors taught at external sites: 'Elements of Electrical Engineering' and 'Network Analysis.' 16

Previous papers have provided scientific evidence pertaining to the use of this platform ${ }^{15-17}$. All of the programs utilize standard assessment tools as part of their accreditation procedures and the core partners have used additional pre- and post-surveys, interviews, and observations to better understand how the approach works as an educational experience for students. In addition, some of the tools developed in the core program are now being adapted for use at other schools for comparison purposes. Aggregation of data across these sites and their emerging patterns of use have identified important outcomes related to: students' learning of content within a specific course; transferability across courses; impact on development of professional competencies and characteristics; and affect related to specific and lifelong learning. Examination of systemic data related to institutional polices, infrastructure, and expectations of faculty and student also has allowed for generation of potential patterns of practice that support or hinder delivery of instruction and learning. As part of these system analyses, project staff and the external evaluator identified several consistently occurring barriers or challenges to successful use of the mobile studio pedagogy as well as successful ways of working within or around these problems. 


\section{2.c. Documenting Barriers}

As noted above, the mobile studio pedagogy and accompanying resources were integrated into coursework for students at the three core institutions, RPI, Howard University, and Rose-Hulman Institute of Technology. Instructors ( $n=6 ; 15$ classes) implemented the Mobile Studio into various approaches to learning including active experimentation, autonomous and collaborative practice, demonstration, didactic lectures, and guided inquiry. Information from several mixed methods, quasi-experimental research and evaluation studies were aggregated to document barriers. Data sources include: pre- and post- surveys $(n=796$, matched data from pre- to postsurveys) assessing students’ demographics (e.g., academic status and major); students' selfreported perceptions on the format and setting of Mobile Studio I/O board use; and the benefits and learning outcomes that resulted from I/O board use. Post-course interviews $(n=55)$ of students and instructors assessed overall perceptions of experiences with I/O boards pertaining to use in the course and outside the course. Observations $(n=90)$ of courses also confirmed survey and interview responses. Pre-surveys were administered to students in the first week of the course; post-surveys were completed the last week of each course. Observations were conducted throughout the semester; and interviews were conducted via telephone or in person at the end of the semester. Specific variables and constructs examined included modalities and frequency of use, confounding variables of instructor experience, student experience and background knowledge in electrical engineering, support and resources for a mobile studio pedagogy, and student access to the Mobile Studio I/O boards as well as indicators of learning and preparation for learning. Analysis of these data indicated three major challenges to implementation: limited experience with the pedagogical approach, lack of internal support and limited resources, and limited access to the device.

\section{BARRIERS}

The process of successful adaptation of innovative educational devices involves awareness and understanding of barriers as well as knowledge of potential benefits. For the Mobile Studio project, this entailed challenges that are inherent to implementation of any new instructional approach (e.g., instructor experience, administrative support, and assistance in acquiring needed resources) as well as specific challenges reflective of the philosophy underlying a mobile studio pedagogy (e.g., the need for accessibility and mobility of the device and support for a constructivist approach to learning). Information pertaining to these areas is presented below.

\section{3.a. Prior Experience}

Instructor and students' lack of experience with constructivist philosophies of education and use of Mobile Studio devices were found to impede or delay adaptation. As a result, initial implementation of the instructional approach forced many related barriers. The depth and seriousness of these barriers however, were found to vary and decrease as positive experiences evolved. As noted above, the Mobile Studio device was implemented across a variety of settings and contexts. Settings of use were originally designed for electrical engineering students in a circuits course; however, the use of the Mobile Studio was expanded to support additional content. Illustrated in Table 1 is the depth and breadth of instruction. Supported in the current program, each of the instructors at RPI had the opportunity to implement the Mobile Studio into 
their instruction multiple times. As instructor experience increased, perceptions of I/O board use were positive, especially student acceptance of format and setting of the incorporation of the technology, the role of the instructor/TAs, and the supplementary materials provided for use. For example, student responses in the 'Electric Circuits' courses taught by the experienced developer were notably higher than responses from initial students in courses taught by non-developers. Overall, students' perceptions of the Mobile Studio by instructor experience in the use and incorporation of the mobile studio pedagogy into the course increased as instructor experience progressed (see Figure 1).

A comparison of the four classes of results in Figure 1 shows two very interesting results. First, the variation in results from term-to-term is less for the developer in 'Electric Circuits' and the new context in 'Electronic Instrumentation' than for the other two categories. The instructor in 'Electronic Instrumentation' has significantly more previous experience with Mobile Studio than the other instructors in 'Introduction to Electronics' and 'Electric Circuits,' although much less than the developer. Thus, experience also helps with consistency. Second, there is a big difference in the importance of the supporting materials in the four categories, discussed later in this paper.

The noted decrease in 'Introduction to Electronics' students' overall perceptions of Mobile Studio I/O board use from Year Three to Year Four supports the role of instructor experience; while the course instructors did not have the personal experience in using the Mobile Studio held by other instructors. In addition, the first set of TAs that taught the lab sessions (noted as Year Three in the figure) had more experience and familiarity using the board for instruction than did TAs in Year Four.

Table 1

Instructor Experience with Mobile Studio

\begin{tabular}{|c|c|c|c|c|}
\hline Institution & $\begin{array}{c}\text { Rank of } \\
\text { Familiarity with } \\
\text { Use (1-5) }\end{array}$ & Course & Instructor/Familiarity & $\begin{array}{c}\text { Phase of course } \\
\text { adoption }\end{array}$ \\
\hline \multirow{3}{*}{$\begin{array}{c}\text { RPI } \\
\text { (original site) }\end{array}$} & 1 & Electric Circuits & Developer & $\begin{array}{c}\text { Piloted/Integrated/ } \\
\text { Refined }\end{array}$ \\
\hline & 2 & Electric Circuits & $\begin{array}{c}\text { Replicate, } \\
\text { non-developer Instructor }\end{array}$ & Replicated \\
\hline & 3 & $\begin{array}{c}\text { Electronic } \\
\text { Instrumentation }\end{array}$ & $\begin{array}{c}\text { Replacement Project } \\
\text { Lead/Instructor }\end{array}$ & $\begin{array}{c}\text { Transfer to another } \\
\text { context/course }\end{array}$ \\
\hline $\begin{array}{c}\text { Howard } \\
\text { University } \\
\text { (Core partner) }\end{array}$ & \multirow{2}{*}{4} & $\begin{array}{l}\text { Network } \\
\text { Analysis }\end{array}$ & \multirow{2}{*}{$\begin{array}{l}\text { External Instructors- } \\
\text { both with the project } \\
\text { since its development }\end{array}$} & \multirow{2}{*}{$\begin{array}{l}\text { Piloted/Integrated into } \\
\text { courses for which } \\
\text { designed by non- } \\
\text { developer and off site }\end{array}$} \\
\hline $\begin{array}{l}\text { Rose-Hulman } \\
\text { (Core partner) }\end{array}$ & & $\begin{array}{l}\text { Elements of } \\
\text { Electrical } \\
\text { Engineering }\end{array}$ & & \\
\hline $\begin{array}{c}\text { RPI } \\
\text { (original site) }\end{array}$ & $\downarrow$ & $\begin{array}{l}\text { Introduction to } \\
\text { Electronics }\end{array}$ & $\begin{array}{c}\text { Lab Instructors were TAs } \\
\text { with prior experience } \\
\text { using the I/O boards }\end{array}$ & $\begin{array}{l}\text { Transfer to a higher } \\
\text { level course }\end{array}$ \\
\hline
\end{tabular}


Figure 1

\section{Student Perceptions of of I/O Board Use}

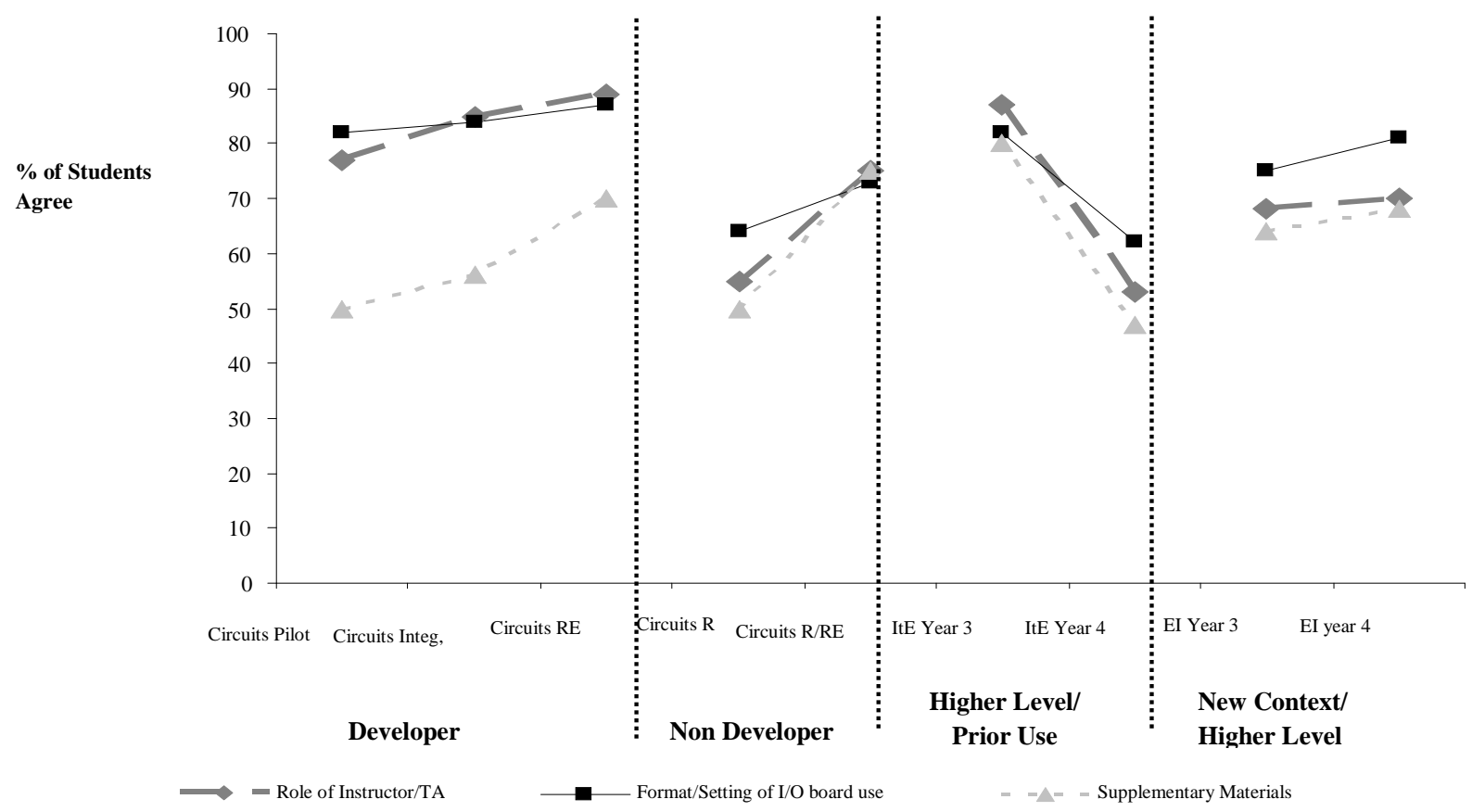

*Note. Circuits $R E=$ refinement; Circuits $R=$ replication; Circuits $R / R E=$ Continued replication; ItE Year 3 and ItE Year 4=higher level transfer; EI Year 4 and EI Year 4=context-transfer.

Limited prior student experience with use of the mobile studio approach also emerged as a barrier to successful implementation. Both students and faculty expected that prior experience with the Mobile Studio I/O board would be related to students' personal investment in the content and pedagogy and that this investment would influence use and knowledge gain. Students in the lower level courses ('Electric Circuits') and the context transfer course ('Electronic Instrumentation') did not have previous experience with the Mobile Studio I/O boards. But nearly all students in the higher level course ('Introduction to Electronics') had prior experience using the I/O boards.

The barrier of students' experience with the I/O boards also was related to the instructors' experience in using the I/O board. Students were more positive in their responses when the instructor had more experience with the Mobile Studio I/O board and when students had experience with I/O boards and/or had a background knowledge related to the content (i.e., students in the context-transfer phase, 'Electronic Instrumentation,' had little to no prior coursework in electrical engineering). A fundamental characteristic of mobile studio pedagogy is that the learning platform (Mobile Studio hardware plus software) is with the student from the first course in which it is utilized through the remainder of their education. The knowledge of and comfort level with the platform grows as it is used again and again in courses, projects and informal inquiry. Equally important is a consistent, long-term relationship of the instructor with the platform where they also use it in courses, research and personal tinkering. The learning curve for both instructors and students is shallow; it generally takes less than an hour to set up the system and take first data for even K-12 application. However, the effectiveness of any 
device or system improves with use. With Mobile Studio so small and portable, it becomes part of the life of both teacher and student and its use improves with age.

When all three factors occurred - the instructor had experience with the Mobile Studio, students had experience with the Mobile Studio, and background knowledge in the content area was present - students had overall positive perceptions of the benefits the I/O board offered in terms of affective and academic learning outcomes (see Figure 2). For example, student response indicated knowledge transfer outside of the course and application to new problems as academic outcomes from I/O board use. Student interviews validated the idea that experimentation with the I/O board helped reinforce and transfer theoretical concepts learned in class to new problems, (e.g., "We learned material theoretically in lecture but with the I/O board we could build them and put in any output and input so you could see just what you learned in class. You could see what a circuit is doing, how to apply what we learned, and how to apply it to a real scenario.").

Figure 2

Students Perceptions of $\mathrm{I} / \mathrm{O}$ Board Use Learning Outcomes by Instructor Implementation

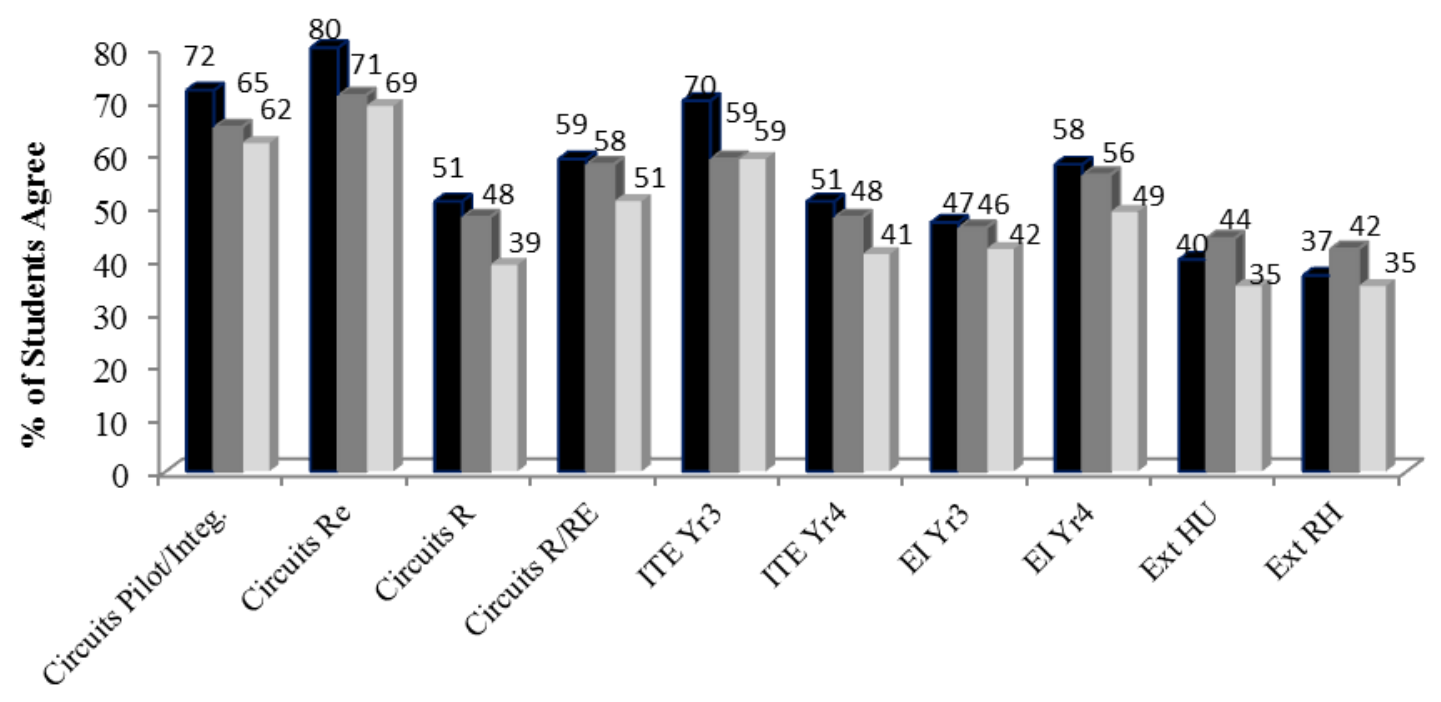

Instructor/Course Implementation

- Specific Content Lrng $\quad$ General Lrng Affective Lrng

*Note. Circuits RE=refinement; Circuits $R=$ replication; Circuits $R / R E=$ Continued replication; ItE Year 3 and ItE Year 4=higher level transfer; EI Year 4 and EI Year 4=context-transfer; Ext Hu=Howard University; Ext RH=Rose-Hulman.

These findings indicate that the barrier of instructor experience, while important to acknowledge, can be decreased by preparation and repetition of use in instruction. Training faculty and staff in how to use the Mobile Studio and various ways of how to incorporate it into instruction would help to eliminate this barrier in additional adoption sites.

The barrier of student experience can be decreased by continual integral use and by an increase in instructor experience in Mobile Studio implementation and an increased awareness of student expectations for learning. Student background knowledge is also important to take into account as a facilitator for the adoption of Mobile Studio education. 


\section{3.b. Supporting Resources}

Another barrier noted during adoption of the mobile studio approach across multiple courses and semesters was the lack of use and access to resources that support the use of the I/O boards. Students' perceptions of supplementary materials were markedly lower than their responses regarding the role of the instructor and the format and setting of use. For instance, student feedback to, "What would you change?[to improve implementation]" consistently indicated a need for more support and resources, especially at early stages of use [e.g., "Provide better diagrams," "Instructions need to be clearer," and “make better, up-to-date diagrams”]. General suggestions included creating video demonstrations on how to use various applications of the I/O boards and incorporating an introductory tutorial to I/O board use. When students' responses were taken into account by instructors, students' overall perceptions of the need for supplementary materials increased as instructor experience increased. A potential solution to this issue is for instructors to collaborate across institutions and inform those institutions adopting the mobile studio approach the importance of using such materials when implementing the Mobile Studio I/O boards into instruction and student learning.

As noted above, there is a marked difference in the relative effectiveness of the instructor, setting and supporting materials. The developer is an excellent, charismatic teacher known for making many changes at the last minute. Thus, his supporting materials generally lagged in availability. This is not atypical when instructors are developing radically new ideas in instruction. Compare the much lower value put on the supporting materials in the developer's 'Electric Circuits' class with 'Electronic Instrumentation’ (Figure 1). In the latter case, course delivery is built around video lectures (there are no live lectures at all) and a very extensive set of supporting materials. The learning environment in this class is based on student inquiry with every team of two students (all work is done by teams) working at their own pace. That the students rate the format/setting of board use as the most effective shows that they like the approach and it is working. In this class, student performance on tests and lab/project reports has continued to improve over typical levels when standard lectures were used. ${ }^{17}$

\section{3.c. Access to Mobile Studio I/O Boards}

At RPI, students were originally expected to purchase the Mobile Studio I/O boards for the purpose of using them outside of class time for experimentation, practice, and/or homework purposes. For the context transfer course Electronic Instrumentation, where students were majoring in another field of engineering, the student purchased one board per group of two so no single student had constant access. The last time the replicate instructor taught Electric Circuits, due to external factors (e.g. delays in board manufacturing), students in the course only had access to the I/O boards during lab time and "open shop" time set aside for them to work on their assignments. Both students and faculty specifically noted the lack of availability of the I/O boards as a barrier. Students indicated they used the I/O boards to complete projects from class, but did not use it for tinkering or personal inquiry purposes. Students did offer solutions to decrease this barrier, e.g., ensure I/O boards are available for purchase in the future or at the very least, create additional flexible hours to use the boards in the lab (there are presently 2-3 hours of open shop nearly every day of the week). Having the option for students to rent the I/O boards, if 
they do not have a background in electrical engineering and would not use the $\mathrm{I} / \mathrm{O}$ boards for subsequent coursework, or for students to buy the I/O board who would use the boards in subsequent coursework and for practice and experience, would eliminate this barrier altogether.

\section{CONCLUSIONS}

This new paradigm in engineering pedagogy opens avenues for inquiry-based learning that enhance and deepen student learning of the fundamental concepts that underpin all of our disciplines; to teach experimental concepts that include simulation, measurement, and debug techniques, the influence of real-world variables and to develop engineers with a systems view of engineering design. The multi-step learning process made possible by this approach maps exceptionally well onto Bloom's Taxonomy as students work their way toward creative engineering and science.

To successfully adopt and incorporate innovative educational devices into curricula within and across multiple institutions, understanding the potential advantages is essential, but understanding the barriers that can occur is just as important to ensure the effectiveness of implementation. In terms of the Mobile Studio project, the potential challenges in implementation reflected experience (both instructor and student), the use and development of supporting resources to the device, and the availability and accessibility of the device.

Investigation of such barriers resulted in potential solutions for future institutions to consider before adopting the Mobile Studio. The barrier of instructor experience can be alleviated by an increase in instructor awareness of the importance and usability of the Mobile Studio I/O boards for student learning conveyed through training and collaboration with institutions already utilizing the pedagogy. If such training was in place, instructors would learn various ways of implementing the Mobile Studio into their instruction. In addition, the collaboration could result in the communication and sharing of resources to use with the Mobile Studio that students and instructors have found beneficial. If both students and instructors are able to fully embrace Mobile Studio pedagogy, which includes the development of a rich, long-term relationship with the mobile platform, the identified barriers would not exist.

Whether the students, TAs or instructors are experienced or not, student perceptions of Mobile Studio effectiveness consistently exceed 50\%, even in courses where they originally come to class without any interest in the subject (e.g., mechanical engineering students in 'Electronic Instrumentation'), especially when they are given the time and resources to work in such a new subject at their own pace. As the adoption of mobile hands-on learning, based on Mobile Studio and similar platforms, spreads to more campuses and more supporting materials are made available, the remarkable results obtained will continue to improve.

Acknowledgment: This work was supported primarily by the Engineering Research Centers Program of the National Science Foundation under NSF Cooperative Agreement EEC-0812056 and the NSF Division of Undergraduate Education under DUE-0717832. 


\section{REFERENCES}

1. M. Chi, and R. Glaser, "Categorization and Representation Physics Problems by Experts and Novices”, Cognitive Science 5, 121-152., 1988.

2. M. Cyr, V. Miragila, T. Nocera, and C. Rogers, “A Low-Cost, Innovative Methodology for Teaching Engineering Through Experimentation.” Journal of Engineering Education, Vol. 86, No. 2

3. R.M. Felder and L.K. Silverman. "Learning Styles and Teaching Styles in Engineering Education." Engineering Education, 78 (7), 674-681, 1988.

4. D. E. Egan and B. J. Schwartz, "Chunking in recall of symbolic drawings” Memory and Cognition 1979 Mar; 7(2):149-58.

5. S. Jackson, “Our emerging crisis: the graying of American science”, Research USA, April 28, 2003.

6. M. J. Jacobson, \& R. J. Spiro, (1994) Hypertext Learning Environments, Cognitive Flexibility, and the Transfer of Complex Knowledge: An Empirical Investigation. Journal of Educational Computing Research, 12(4)

7. D.A. Kolb, Experiential Learning: Experience as the Source of Learning and Development. Englewood Cliffs, NJ, Prentice-Hall, 1984.

8. S. Kresta, (1998) "Hands-on Demonstrations: An Alternative to Full Scale Bench Experiments", Journal of Engineering Education, p. 7-9

9. M. C. Linn, ’Designing Computer Environments for Engineering and Computer Science: The Scaffolded Knowledge Integration Framework, Journal of Science Education and Technology, Vol. 4, No. 2, 1995.

10. E. W. Maby, A. B. Carlson, K. A. Connor, W. C. Jennings, P. M. Schoch, “A Studio Format for Innovative Pedagogy in Circuits and Electronics,” Frontiers in Education November 1997 1431-1434

11. D. Millard, "Workshop: Improving student engagement and intuition with mobile studio pedagogy," Frontiers in Education, October 2008, W3C

12. D. Millard and M. Chouikha, “Work in Progress: Hands-on Exploration of the 'Big Ideas' in Electric Circuits, Frontiers in Education, October 2006, M4D1-4

13. D. Millard, J. Coutermarsh, K. Connor, "Re-engaging engineering students in hands-on education,” ASEE Annual Conference, June 20061933

14. D. Newman, M. Deyoe, K. Murphy, K. Connor., (2010, November). "External Validity: Documenting Replicability and Transferability in Technology Programs.” Presented at the AEA Conference in San Antonio, TX.

15. J. Rodd, D. Newman, G. Clure, M. Morris (2010, March). "Moving the Lab to the Classroom: The Impact of an Innovative Technological Teaching Tool on K-14 Learning and Cognition,” Presented at the SITE Conference, San Diego, CA.

16. D. Newman, M.M. Deyoe, and G. Clure (2011). Rensselaer Polytechnic Institute Mobile Studio Environments to Enhance STEM Education, 2008-2011 Summative Report. The Evaluation Consortium, University at Albany, SUNY.

17. K. Connor, C. Scott, M. Chouikha, A. Wilson, A. Anderson, Y. Astatke, F. Berry, D. Newman, J. O’Rourke, T. Little, D. Millard. (2011) “Multi-Institutional Development of Mobile Studio Based Education and Outreach,” ASEE Annual Conference, Vancouver, BC, June 2011 AC2011-2039.

18. K. Connor, F. Berry, M. Chouikha, D. Newman, M. Deyoe, G. Anaya, W. Brubaker. (2011) "Using the Mobile Studio to Facilitate Non-Traditional Approaches to Education and Outreach,” ASEE Annual Conference, Vancouver, BC, June 2011 AC2011-2250. 